\title{
A Proposed Analysis and Digital Image Processing For Indication of Tailings Dam Failure
}

\author{
$1^{\text {st }}$ Fernando Paim Lima \\ Dep. of Computation IFMG- \\ Campus Formiga \\ (Teacher) \\ Instituto Federal de Educação \\ Ciência e Tecnologia Minas \\ Gerais \\ Formiga-MG, Brasil \\ fernando.lima@ifmg.edu.br
}

\author{
$2^{\text {nd }}$ Bruna Mendes \\ Dep. of Computation IFMG- \\ Campus Formiga \\ (Student) \\ Instituto Federal de Educação \\ Ciência e Tecnologia Minas \\ Gerais \\ Formiga-MG, Brasil \\ brumendes102@gmail.com
}

\author{
$3^{\text {rd }}$ José Luis Pimenta \\ Dep. of Computation IFMG- \\ Campus Formiga \\ (Student) \\ Instituto Federal de Educação \\ Ciência e Tecnologia Minas \\ Gerais \\ Formiga-MG, Brasil \\ joseluizmacielp@gmail.com
}

\author{
$4^{\text {th }}$ Paloma Oliveira Maira \\ Lima \\ Dep. of Computation IFMG- \\ Campus Formiga \\ (Teacher) \\ Instituto Federal de Educação \\ Ciência e Tecnologia Minas \\ Gerais \\ Formiga-MG, Brasil
}

paloma.oliveira@ifmg.edu.br

\begin{abstract}
Due to the recent accidents with ore tailings dams in Brazil, many researchers have been interested in alternatives to minimize the impact of such disasters. This paper proposes a method for analysis of surveillance images related to Córrego do Feijão mine dam, located in the city of Brumadinho, Minas Gerais, Brazil. The method uses digital image processing and computer vision algorithms to obtain an indication of the moment of its rupture. The results found show that the technique is relevant to the identification of dam rupture. The methodology in this paper can be used to develop autonomous monitoring solutions for the purpose of failure warning, which might provide time for people to take refuge in higher places before being reached by the slurry wave.
\end{abstract}

Keywords-Computer vision; Digital image processing; Tailings dam.

\section{INTRODUCTION}

In Brazil there are several dams classified as high risk. According to the National Water Agency (ANA), the dam that collapsed in the city of Brumadinho in the state of Minas Gerais, on January 25, 2019, was among the 56 dams owned by the a mining company, that as classified as "high potential associated damage" [5]. In the Brumadinho disaster, basic security issues did not work, as it was highlighted in the Brazilian press that the sirens did not sound to alert workers and nearby communities at the time of the accident. Given the need to prevent this type of catastrophe, the development of new methods for identifying disruptions is proven necessary to minimize environmental impacts, avoid or mitigate humanitarian tragedies and improve safety aspects in general. In this sense, the proposed method of computer vision and digital image processing for video analysis in dam monitoring is a viable and possibly lower-cost alternative compared to autonomous monitoring systems currently used based on sensors, whose estimated value is about $\mathrm{R} \$ 1$ million reais as surveyed by the news site Itatiaia [2]. The purpose of using these techniques is the recognition of discontinuities or similarities in the captured image, whose analysis process can be used to detect small-scale changes before they are visible to the naked eye. The concept of analysis is related to the process where there is a description of the information presented in the capture. This step is called parameterization, and several quantitative measures are used to describe different information within an image [1]. According to the context presented, this paper proposes an image analysis of surveillance videos of the ore tailings dam B1 from Córrego do Feijão Mine in Brumadinho (MG) in order to obtain a visual indicator of the moment of its rupture, determining a pattern of detection for dam failure.

\section{Methodology}

The images from the internal security circuit of the company Vale in Brumadinho published by the press is the data source used for the proposed analysis. The images from the camera installed directly in front of dam B1 at Córrego do Feijão mine allow the sequence of changes in the landscape during the rupture to be analyzed. Although the resolution, image definition, and the frame rate were not designed for the analysis and perception of changes at small scales, it presents themselves to be robust for the analysis of total dam failure.

\section{A. Video from Vale security camera}

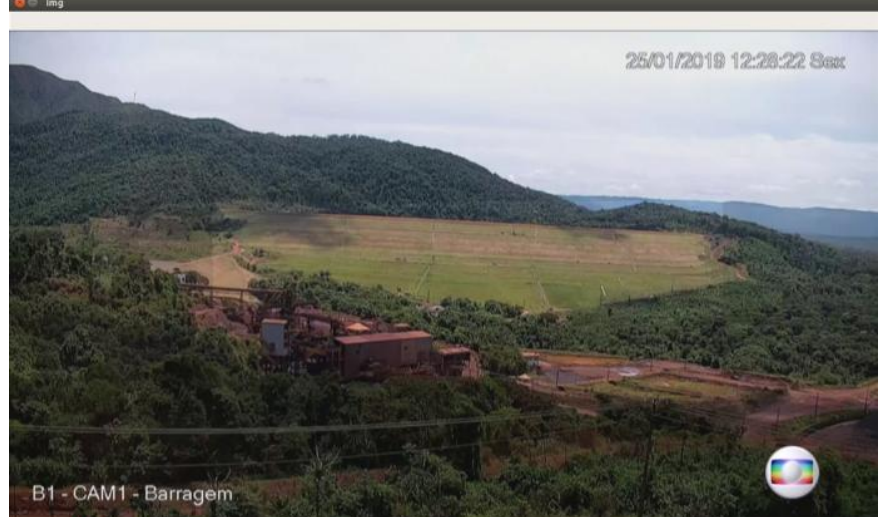

Figure 1: Image of the dam found in the media, from before the rupture, captured by a Vale security camera.

\section{B. First Segmentation}

It is set (manually) the area of interest to be processed, as can be seen in Figure 2.

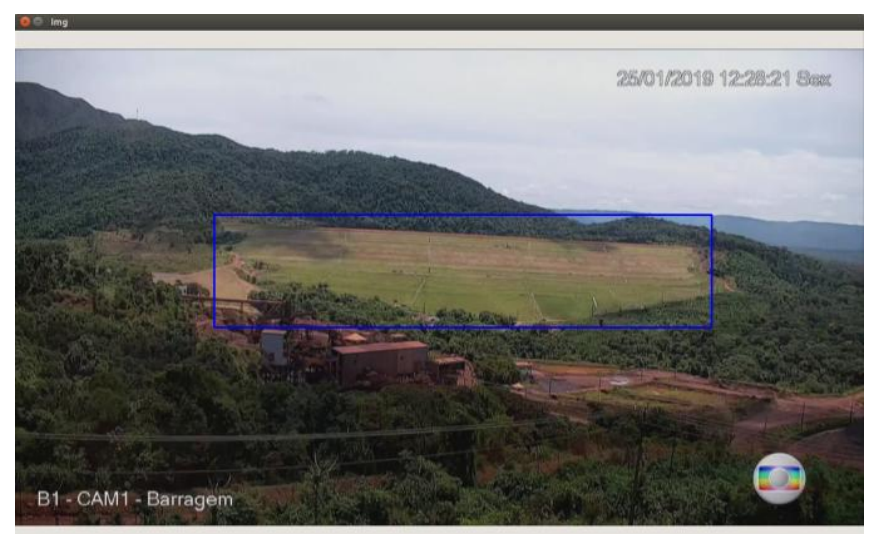

Figure 2: Area of interest defined by a frame. 
The algorithms are only applied inside the area of interest, with an objective to minimize the computational cost of the processing, which consists of two steps: A) performing a normalization of intensities in three color channels, limiting them to a scale from 0 to 255 in order to eliminate pixels with discrepant intensities and distribute the pixels more evenly over the range of the image. B) using the median filter with a 3x3 pixel mask (kernel) after normalization, which will minimize details and fragmented noise in the image, in addition to generating a blurring effect. This method also works for minimizing temporal changes caused by cloud shadows, birds, machines, workers moving, among others.
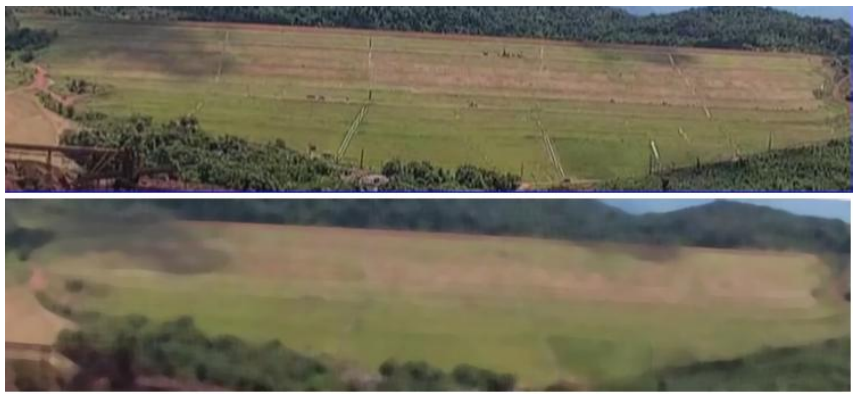

Figure 3: Unprocessed region of interest and preprocessed region of interest.

\section{Second Segmentation}

The segmentation step proposed for this problem consists of identifying temporal differences in the preprocessed video area of interest every 2 seconds, which corresponds to approximately 60 frames. To obtain such differences, two frames are collected, one frame called A and another frame called B, with B being collected 60 frames after the collection of A (approximately 2 seconds). Equation (1) represents the collection of frames and the difference between them.

$\sum_{i=i+60}^{n} \quad a_{i-60}-b_{i}$

Both frames are converted to grayscale (intensities of 0..255), then the images are subtracted. According to Dotto, P. et al. [4], image subtraction can emphasize minimal differences in images, including differences barely noticeable to the human eye. Furthermore, the resulting matrix of the subtraction is subjected to a process of dilation of light areas to highlight the differences found from one image to another in the course of time. Subsequently, a threshold operation is performed, with global threshold from intensity 15 to intensity 255 , highlighting the region of interest, as the image is predominantly dark using global threshold value.

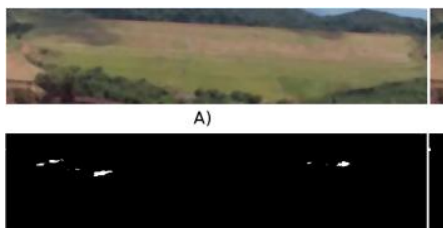

C)
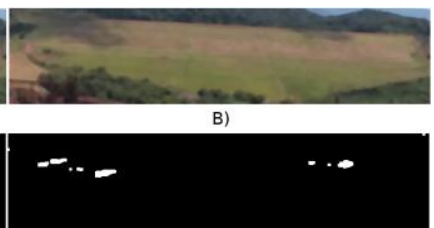

D)
Figure 4: (A) Preprocessed frame A region of interest; (B) Preprocessed frame B region of interest; $(C)$ Binarized difference between frame A and $\mathrm{B}$; (D) Binarized dilated difference between regions of interest in frames A and $\mathrm{B}$.

\section{Feature extraction}

Feature extraction is an operation to highlight temporal differences, and a simple way to observe proportions is the sum of the different pixels. In order to avoid problems such as overflow during the summation of the intensities, the summation scale was reduced 10,000 times as represented by the Equation (2): $\frac{\sum_{i=i+60}^{n} D\left(T\left(a_{i-60}-b_{i}\right)\right)}{10.000}$

where $\mathrm{T}$ corresponds to the Threshold (binarization) and $\mathrm{D}$ corresponds to the image dilation process.

\section{1) Threshold}

According to Artero, A. and Tomasselli, A. [3], there is a large set of techniques for obtaining a binary image. One such technique is to use a global threshold value that defines whether a pixel will be black or white within an image.

$\operatorname{srt}(x, y)=\left\{\begin{array}{l}1 \text { if } f(x, y)<T \\ 0 \text { if } f(x, y) \geq T\end{array}\right.$

where $\mathrm{x}, \mathrm{y}$ are pixel coordinates and $\mathrm{T}$ is the global threshold value and $\operatorname{str}(\mathrm{x}, \mathrm{y})$ is the output argument.

\section{2) Dilation}

Image dilation is a morphological operation [6] used to fill holes and gaps, as well as growing features. The dilation of A by B is shown in Equation (4):

$A \oplus B=\left\{c \in Z^{2} \vee c=a+b, a \in A e b \in B\right\}$

where: $\mathrm{A}$ and $\mathrm{B}$ are sets of $Z^{2}$ (binary images); $\mathrm{A}$ is the image to be operated on; $\mathrm{B}$ is the structuring element (its nature defines how the expansion will occur).

\section{RESULTS}

The temporal subtraction results demonstrate interesting frame-by-frame differences in Figure 5.

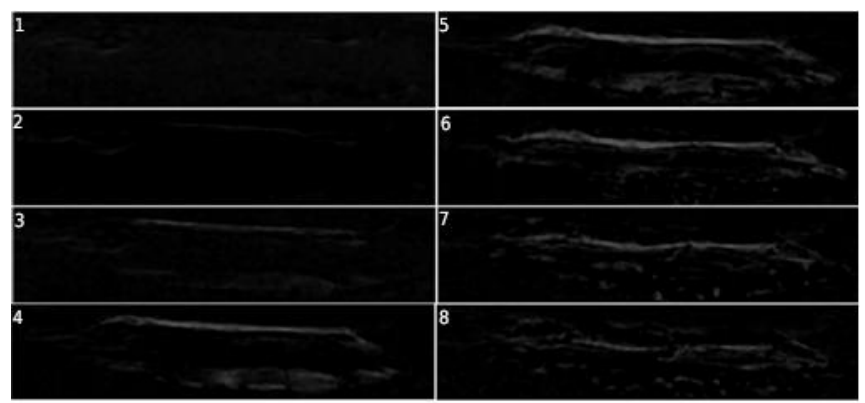

Figure 5: Sequence of temporal difference analysis.

The use of dilation and binarization is responsible for creating significant and visible changes as shown in Figure 6.

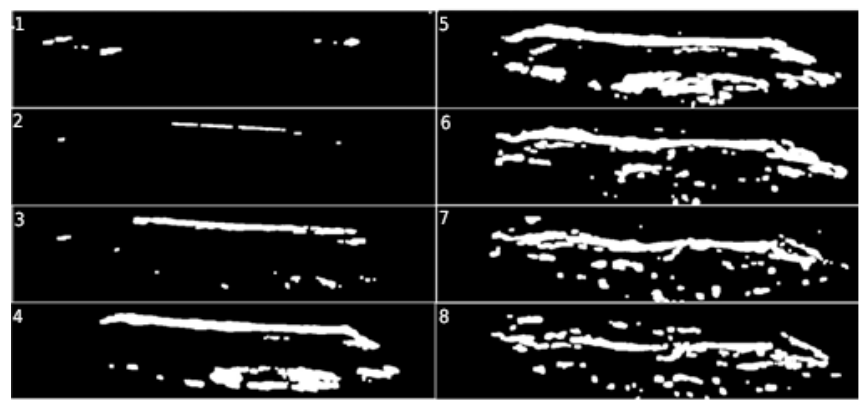

Figure 6: Sequence of dilated and binarized temporary differences analyses.

The striking feature of the rupture can be seen initially in the second image of the sequence through the line at the top of the dam (Figure 6). In Figure 7, the x-axis represents the analysis made every 60 video frames (approximately two seconds), in which we can observe differences between the non-segmented frames (Temporal Diff.), sum of differences (Sum Dif.) and those that went through the threshold process and dilation (Dif. Thresh. and Dif. Thresh. Dil.). In the same 
way that the first indication of the dam failure is only visible from the second image onwards in Figure 6, the graph also shows the disparity of the differences after approximately 180 frames, as can be seen by the large variation between the second and third frame collection(third iteration), resulting in a peak that culminated during the fourth iteration.

The temporal difference (Dif. Temporal) calculated from the video registers little variation between frames, which suggests that not only the differences are barely visible, but also contributes to the conclusion that there would not be a way to assimilate the dam rupture through a normal approach. With the binarization of the difference between frames (Dif. Thresh), the moment of the rupture is highlighted, and with this, it is possible to provide satisfactory information about the moment of the incident. However, when using the dilation operation, the moment of rupture is even more evident.

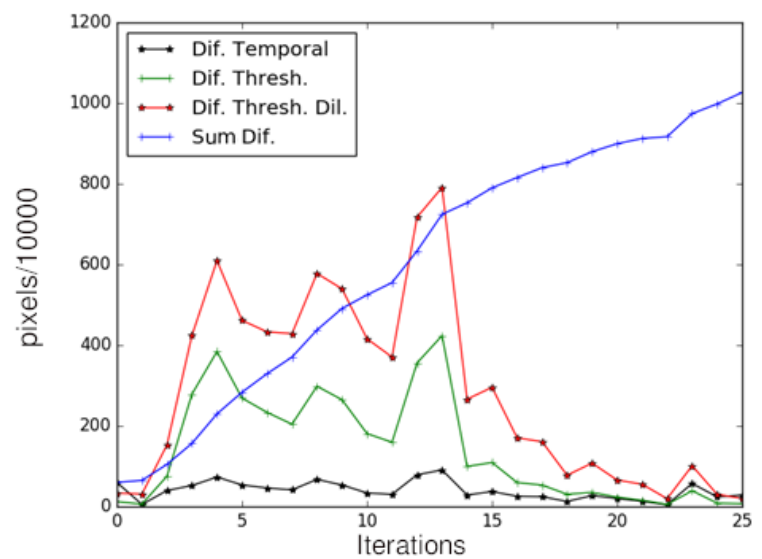

Figure 7: Differences processed and the sum of differences as a function of analysis performed.

\section{CONCLUSIONS}

In order to assist in the process of monitoring dams, this paper proposed a method for analyzing security images and extracting features to provide an indication of the moment of structural failure. The recognition method proposed stands out for being a methodological proposal that will allow the creation of autonomous monitoring solutions in critical real- time at a safe distance from the dam, which in case of failure, will not suffer from damage caused by it, and so it becomes a safer way of detecting discontinuities. Although the data used for the tests is limited to just one video, all the metrics applied in this proposal had a satisfactory result and met the main objective, which was a successful identification of pattern changes in the investigated dam at the time of the collapse. As for future research, there could be opportunities to improve and validate the proposed method by applying rupture simulations in reduced laboratory-level models, as well as proof-of-concept maturity.

\section{ACKNOWLEDGMENT}

IT IS IMPORTANT TO HIGHLIGHT THE TECHNICAL SUPPORT OF THE APPLIED RESEARCH GROUP ON INNOVATIVE AND INTELLIGENT SYSTEMS OF IFMG - CAMPUS FORMIGA, IN ADDITION TO THE FINANCIAL SUPPORT OF THE RESEARCH AND EXTENSION DEPARTMENT OF IFMG - CAMPUS FORMIGA WITH RESEARCH GRANTS.

\section{REFERENCES}

[1] ALBUQUERQUE, M.P. "Processamento de imagem: métodos e análises," Centro Brasileiro de Pesquisas Físicas - CBPF/MCT Coordenação de Atividades Técnicas - CAT, Rio de Janeiro, 2013. $\begin{array}{llll}\text { [accessed } & \text { Out. } & \text { 2019]. }\end{array}$ http://www.cbpf.br/cat/pdsi/pdf-/ProcessamentoImagens.PDF

[2] ÁVILA, R. "Barragem de Brumadinho não tinha sistema que poderia ter evitado centenas de mortes," 2019. Itatiaia. [accessed Out. 2019]. [Online]. Avaliable: http://www.itatiaia.com.br/noticia/barragem-debrumadinho-nao-tinha-sistema-que

[3] ARTERO, A; TOMMASELLI, A. Limiarização Automática de Imagens Digitais. Boletim de Ciências Geodésicas. ISSN 1982-2170. 2000

[4] DOTTO, P.; Jesus Pereira Haygert, C.; d'Ornellas, M. "Subtração Digital e Registro de Imagens em Radiologia”. ISBN 978-85-6710414-0. 2015.

[5] FARIA, Flávia. "1 a cada 3 barragens da Vale pode causar tanto estrago quanto a de Brumadinho," 2019. Folha de S. Paulo.[accessed Out. 2019]. [Online]. Avaliable: https://www1.folha.uol.com.br/cotidiano/2019/01/1-a-cada-3barragens-da-vale-pode-causar-tanto-estrago-quanto-a-debrumadinho.shtml

[6] MARQUES FILHO, Ogê; NETO, Hugo Vieira. "Processamento digital de imagens". Brasport, 1999. 